\title{
SER OU NÃO SER: PODERIA UM CHIMPANZÉ FAZER A PERGUNTA DE HAMLET?
}

\author{
Eliane Sebeika Rapchan* \\ Universidade Estadual de Maringá - Brasil \\ Walter Alves Neves** \\ Universidade de São Paulo - Brasil
}

Resumo: Os estudos sobre comportamento de primatas não humanos, particularmente aqueles dedicados aos chimpanzés, realizados a partir da década de 1960, têm exposto um conjunto de conhecimentos sobre as capacidades cognitivas e a complexidade dos comportamentos individuais e coletivos desses animais que sugerem reflexões tanto sobre o lugar e o papel da vida social em seu desenvolvimento quanto sobre a extensão e a profundidade das características singulares de cada chimpanzé. Ambas as dimensões são, aliás, profundamente associadas pelas perspectivas das ciências sociais e humanas. A discussão sugerida visa pontuar os resultados obtidos em pesquisas sobre chimpanzés selvagens e de laboratório relacionados a temas como emoções e sentimentos, consciência, teoria da mente, noção de pessoa e capacidade simbólica com o intuito de contribuir com as discussões sobre a viabilidade, ou não, de se considerar a existência de uma "subjetividade animal".

Palavras-chave: laboratório, relações entre humanos e animais, subjetividade, trabalho de campo.

Abstract: Studies on non-human primates behavior, particularly those dedicated to chimpanzees conducted from the 1960s, have exposed discoveries about their cognitive skills and their individual and collective complex behavior what suggests reflections about both the place and the role of social life in their development, as the extent and the depth of the unique characteristics of each chimpanzee. Both dimensions are indeed deeply associated with the prospects of social and human sciences.

* Contato: esrapchan@gmail.com

** Contato: waneves@ib.usp.br

Horizontes Antropológicos, Porto Alegre, ano 23, n. 48, p. 303-333, maio/ago. 2017 http://dx.doi.org/10.1590/S0104-71832017000200013 
The discussion suggested aims to point out the results obtained in research on wild chimpanzees and laboratory-related topics such as emotions and feelings, consciousness, theory of mind, the notion of person and symbolic capacity in order to contribute to discussions on the feasibility, or not, to consider the existence of an "animal subjectivity."

Keywords: field work, laboratory, human animal relations, subjectivity.

\section{Introdução}

Os chimpanzés possuem imensas e inegáveis semelhanças com os humanos em termos genéticos, anatômicos, cognitivos, comportamentais e sociais e, por isso, foram escolhidos para esta reflexão sobre subjetividade animal. Isso não quer dizer, contudo, que adotaremos aqui uma perspectiva gradualista dos chimpanzés em relação aos outros animais não humanos. Temos à disposição boas teorias tanto para explicar a história evolutiva conjunta de certas espécies quanto para demonstrar que cada espécie é única. Há também bons argumentos para o desenvolvimento de pontos de vista mais relacionais (Ingold, 1994, 1996, 1998).

Desse modo, nossa proposição aqui não é eleger os chimpanzés como espécie privilegiada na comparação com os humanos e, assim, estabelecer um rubicão de novos critérios para quem sejam "nós" e "eles", nem ignorar todo o universo constituído pelas pesquisas dedicadas a explorar os temas sugeridos neste artigo em várias espécies não humanas. Nossa escolha se justifica pelo volume de pesquisas já acumuladas sobre os chimpanzés, que são a espécie não humana mais estudada quando o assunto é cultura (McGrew, 1998, p. 309; Rapchan, 2004), pela celebrada semelhança genética identificada entre nós (The Chimpanzee Sequencing and Analysis Consortium, 2005) e pelas reações, ideias e sentimentos que os chimpanzés são capazes de provocar no pensamento dito ocidental, como o crânio de Yorick nas mãos do jovem Hamlet.

Assim, selecionamos sete conjuntos de fenômenos e reflexões sobre o comportamento de chimpanzés para analisar o tema "subjetividade animal". São eles: a vida social; as emoções, os sentimentos e a consciência; a cognição, em especial, o uso de ferramentas e questões sobre aprender e ensinar; a teoria da mente; a noção de pessoa (Mauss, 1978); as relações híbridas entre humanos e animais; e as concepções antropológicas e primatológicas de cultura. 
Trata-se de uma lista extensa constituída por temas complexos. Destacado de um volume de produção muito maior, o material selecionado reflete debates correntes e posicionamentos de alguns dos teóricos mais influentes em suas respectivas áreas de conhecimento e visa demonstrar como eles se articulam em torno de um eixo de questões em relação às quais a antropologia pode colaborar significativamente. Tais questões correspondem às articulações entre capacidade simbólica e cultura. Vale, ainda, sinalizar que esses temas não serão necessariamente tratados na sequência supramencionada, mas aparecerão no texto à medida que se articulem com resultados de pesquisa ou debates relevantes para a antropologia.

Cada tópico será cotejado sob duas perspectivas: de um lado, a que reconhece a importância daquele dado fenômeno para os humanos acompanhada de indicações de alguns dos caminhos teóricos das ciências sociais que selecionamos para reflexão. De outro, a apresentação do quanto se sabe, até o momento, sobre a existência desses mesmos fenômenos entre os chimpanzés e quais as consequências disso para se pensar sobre semelhanças e diferenças entre nós que não se encontram exclusivamente no plano material (genético, anatômico, fisiológico), mas se manifestam também em aspectos comportamentais e sociais, por exemplo. Aliás, também nesse sentido, esse exercício visa contribuir para reforçar o poder explicativo das abordagens relacionais que buscam superar as fronteiras entre categorias analíticas como natural e social, corpo e mente, material e imaterial, etc.

Essa trajetória culminará num debate crucial, complexo e delicado que enfocará um dos temas mais contemporâneos e quentes do debate sobre as semelhanças e diferenças entre humanos e chimpanzés, a saber: a discussão sobre se certos indícios registrados por primatólogos podem ser aceitos como fenômenos simbólicos e como isso afeta as concepções antropológicas de cultura, no sentido humano.

\section{Chimpanzés são seres profunda e essencialmente sociais}

O chimpanzé é um animal social. A espécie evoluiu na direção da sociabilidade, o que significa, segundo Robin Dunbar (Dunbar, 1998; Dunbar; Schultz, 2007), antropólogo, psicólogo evolutivo e especialista em comportamento de primatas, que eles têm um cérebro social. Essa característica os habilita a reconhecer e distinguir a face de cada membro de seu grupo, identificar 
quem não é do grupo, interessar-se por acontecimentos tais como atividades sexuais, troca de informações, formação e dissolução de grupos e movimentos em torno do reforço ou do enfraquecimento da posição do macho alfa. $\mathrm{Ou}$ seja, um chimpanzé é totalmente habilitado a reconhecer sua própria singularidade e as de outros da sua espécie. Tais habilidades, interesses e predisposições são muito importantes para a sobrevivência em grupos sociais como os dos chimpanzés.

Assim, ainda de acordo com Dunbar (1998), para crescer e viver em grupos nos quais territorialidade, conflitos intergrupais, hierarquia, subgrupos dinâmicos, status e posição de alfa relativamente instável são dimensões relevantes da vida social é preciso saber, e ser capaz de reavaliar constantemente, com quem se pode fazer alianças, quem é aliado de quem, quem está em conflito com quem. As vantagens diretas decorrentes da vida social, sobrevivência física, possibilidade de partilha de alimentos, proteção, ajuda e interações dependem fortemente das habilidades de cada indivíduo observar e usar as informações obtidas na e a partir da vida em grupo (Dunbar, 2003). Em outras palavras, otimizar oportunidades sexuais, saber quem é aliado e quem é inimigo são informações - ou, antropomorfizando, são "fofocas" (Dunbar, 2004) - essenciais à vida social, mesmo entre os chimpanzés.

Além disso, podemos acrescentar, ser um animal social, para um chimpanzé selvagem, significa também possuir capacidades cognitivas que permitem aprender com seus semelhantes as habilidades necessárias para a sobrevivência física, emocional e social segundo os padrões comportamentais de seu grupo, tais como o modo de fazer grooming, que é um display social muito importante relacionado à catação praticada nos pelos dos companheiros para retirar piolhos, formigas, terra ou gravetos e sinaliza submissão, alianças e vínculos. Costuma ocupar extensa parte do tempo dispendido num dia em atividades sociais, segue padrões comportamentais grupais e está associado ao status de seus praticantes. Além do grooming, pescar cupins, fazer ninhos, proteger partes do corpo de arranhões e ferimentos ou cuidar dos filhotes também se constituem em práticas socialmente aprendidas.

Devemos também acrescentar que, tanto nas florestas quanto em laboratórios, pesquisadores têm registrado singularidades e diferenças entre os chimpanzés em relação a uma gama extensa de aspectos que vai das diferentes habilidades para os cuidados maternos às diversas predisposições em favor do contato com humanos (Goodall, 1991), passando por perfis diversificados em 
relação a traços de comportamento como curiosidade, ludicidade, agressividade e outras.

O que se pode pensar sobre isso? Em primeiro lugar, que a vida social e a experiência de cada chimpanzé em particular nesse contexto forjam singularidades, ou seja, seres com características próprias. Em segundo lugar, que, por serem animais sociais, tais singularidades são verificáveis, em princípio, em qualquer chimpanzé, seja o que nasce, cresce e vive nas florestas entre os de sua espécie, seja o que convive com humanos em zoos, parques ou laboratórios.

\section{Emocões, sentimentos e consciência: o inato, o social e o simbólico}

O neurocientista e neurobiólogo Antônio Damásio define emoções como um conjunto de reações corporais. Tais reações são associadas a impulsos neurais que estimulam o organismo para a ação. Eles se manifestam desde o início da vida e são profundamente relacionados às experiências pessoais. A alegria (sob a forma do prazer), o medo, o repúdio, a tristeza e a raiva são emoções.

Os sentimentos são expressões emocionais mais prolongadas moduladas pelo sistema cognitivo. Preocupação, antecipação, cinismo, frustração, pessimismo são sentimentos. Segundo Damásio, não é possível conceber, para os humanos, emoções ou sentimentos isolados da razão. Ainda, para Damásio (2010, p. 18), duas das principais características da consciência se encerram na relação entre o sujeito pensante, no caso, o humano, e "os numerosos conteúdos exibidos da minha mente, independentemente de sua nitidez ou ordem [...]" e no fato de tal ligação ser sentida.

Em relação aos chimpanzés, os pesquisadores registraram variações nas reações emocionais em relação a diferenças sexuais, dominância e personalidade (Buirski; Plutchik; Kellerman, 1978). Em relação à expressão física das emoções, há trabalhos que observam a existência de vínculos entre lateralidade nas expressões faciais e expressão de emoções (Lyddy, 2002) ou, ainda, evidências cutâneas da expressão de emoções (Leavens; Aureli; Hopkins, 2004).

Damásio sugere que não se podem estabelecer analogias consistentes entre o comportamento de chimpanzés e o comportamento humano a partir da ótica dos "sentimentos". O autor é categórico ao delinear diferenças profundas entre as emoções, os sentimentos e a consciência dos humanos e de outros seres vivos. 
Para Damásio, as emoções humanas são processos determinados biologicamente e dependem de mecanismos cerebrais estabelecidos de modo inato, anatômica e fisiologicamente, apesar de o aprendizado e a cultura alterarem as expressões dessas emoções e lhe conferirem significados próprios (Damásio, 2000 , p. 75). Segundo o autor, as emoções humanas são singulares com relação às de qualquer outro ser vivo devido a seus vínculos com juízos, valores e princípios abstratos complexos (Damásio, 2000).

Para pontuar claramente como observa tais distinções, Damásio (2000, p. 57) afirma: "Imagino que algumas criaturas não humanas que exibem emoções, mas que provavelmente não têm o tipo de consciência que possuímos, podem muito bem formar as representações que denominamos sentimentos sem saber que fazem isso." Do ponto de vista antropológico, pode-se afirmar com fortes convicções baseadas em mais de um século de registros etnográficos que há associações consistentes entre esses elementos (juízos, valores, abstrações, representações) e as capacidades simbólicas humanas e que eles são centrais na articulação dos modos de vida coletivos que chamamos de cultura.

Assim, a mediação entre reações emocionais e sentimentos está intimamente relacionada à consciência. Há diferentes tipos de consciência num ser vivo. Restringindo a análise a apenas duas categorias, há uma consciência que se refere às necessidades básicas de sobrevivência e reprodução (alimento, abrigo, encontro de parceiros sexuais, identificação de perigo ou risco, entre outros) e aquela associada à percepção de si e dos outros com os quais se estabelecem relações (mãe e irmãos, grupos familiares extensos, dominantes e iguais, grupo social e espécie). Essas duas categorias de consciência, por si só, constituem um universo analítico bastante amplo e comum a muitos seres vivos.

No caso dos humanos, a consciência sobre si e sobre o grupo é mediada por várias categorias que são organizadas em planos, extremamente nuançados, a maioria deles definidos por recortes nos quais as fronteiras são estabelecidas por critérios de pertencimento fortemente relacionados a categorias cujos significados não se baseiam exclusivamente em lógicas de sobrevivência e reprodução. A família, a aldeia, o clã, as amizades formais, a classe, o gênero, a etnia, a região, a religião, a pátria, a língua ou a humanidade são coletivos resultantes de mecanismos de classificação de si e dos outros carregados de valores e de representações. Ou seja, remetem à nossa capacidade simbólica. 
Assim, o fato de pesquisadores como Damásio enfatizarem a dimensão anatômico-fisiológica dos sentimentos não sustenta, com base na semelhança genética entre ambas as espécies (entre 95\% e 98\%), o estabelecimento de comparações lineares entre os sentimentos de chimpanzés e de humanos. As características que definem essencialmente um chimpanzé e um humano e permitem reconhecimento e identificação de cada um com seus pares e semelhantes são distintas, mesmo considerando todas as variações individuais no interior de uma mesma espécie e levando em conta os casos em que chimpanzés e humanos crescem e vivem em íntima proximidade.

O caso da emblemática chimpanzé Washoe, aliás, não é uma exceção, mas confirma essa regra social (Fouts, 1998). Washoe foi um dos filhotes resgatados dos projetos da Nasa na década de 1970, quando os EUA abandonaram os testes com foguetes tripulados por animais. Ela participou do projeto-piloto do casal Gardner. Esses psicólogos norte-americanos pretenderam testar a hipótese segundo a qual chimpanzés não falam não por serem incapazes, mas por não possuírem sistema vocálico. Assim, criaram filhotes num sistema de paternidade cruzada em laboratório onde todos só se comunicavam através da Linguagem Americana de Sinais (ALS).

Washoe tornou-se proficiente e cresceu sem se identificar com chimpanzés selvagens, reconhecendo-se como membro do coletivo formado por chimpanzés e humanos que convivia cotidiana e intensamente no laboratório do projeto desenvolvido pelo casal Gardner (Fouts, 1998). Como sabemos disso? Quando perguntada, através da ALS, com quem ela se parecia, a partir de estímulos sugeridos por fotografias, Washoe afirmava ser parecida a humanos e aos chimpanzés do laboratório, mas se achava muito diferente dos chimpanzés selvagens.

Segundo Damásio (2000), se é possível aceitar a emergência da consciência como um avanço biológico significativo, por outro lado, a extensão da consciência possibilitada pela memória e pelo registro autobiográfico, pelo registro dos fatos e pela memória operacional está diretamente associada ao desenvolvimento do neocórtex em humanos. Por isso a consciência é tão importante para Damásio na discussão sobre os sentimentos: as emoções só podem ser conhecidas pelo indivíduo por meio da consciência.

Ou seja, não basta existirem as reações articuladas que constituem a emoção, é preciso haver um self para que a emoção seja percebida como parte de algo em nosso organismo, em nosso ser (Damásio, 2000). A existência de 
um self, por sua vez, implica uma consciência de si, em relação ao outro e ao mundo que dependem de referenciais simbólicos e de capacidades de abstração com projeção nas representações de si, dos outros e das coisas. Implica a capacidade para a produção de significados. O self, por essa via, é o substrato da subjetividade humana.

\section{Etnocentrismo, totemismo: pertencimento social e pensamento abstrato}

Jane Goodall figura entre as pioneiras a pesquisar comportamento de chimpanzés selvagens em seus hábitats nativos. Ela iniciou o trabalho na reserva de Gombe (Tanzânia) na década de 1960 a convite do famoso paleoantropólogo Louis Leakey, que pretendia encontrar modelos vivos de comportamento social que o ajudassem a pensar sobre o material que encontrava nos sítios africanos onde trabalhava. Uma das peculiaridades de Goodall era sua falta de formação acadêmica especializada no início da carreira. Leakey procurava alguém muito interessado, mas que não tivesse os vícios acadêmicos da psicologia ou da biologia (Goodall, 1988; Jahme, 2001). Essa configuração proporcionou descobertas surpreendentes sobre nossos parentes mais próximos, que revolucionaram a primatologia e tendem a afetar profundamente a antropologia.

Por exemplo, as "guerras chimpanzés" registradas por Jane Goodall (1988) em Gombe, tornaram-se paradigmáticas e foram adotadas como parâmetros para discussões sobre conflitos intra e extragrupais a partir da influência de fatores evolutivos e dinâmicas sociais relativos a comportamentos que resultam em ferimentos graves ou mortes. Goodall $(1988,1991)$ registra, com tristeza e desespero, a cisão de um grupo a partir da recusa de alguns em aceitarem o novo macho alfa. Formam-se, então, dois grupos de indivíduos que se conhecem e, em muitos casos, são parentes. A pesquisadora narra organização de patrulhas armadas com paus pelo grupo maior e original que passa a patrulhar, em fila indiana, as fronteiras de seu território e mata qualquer membro do grupo dissidente que venha a encontrar até não restar ninguém (Goodall, 1988, 1991).

Em termos antropológicos, os fenômenos associados ao sentimento de pertencimento a determinado grupo associado à incorporação da visão de mundo desse mesmo grupo, via socialização, é denominado etnocentrismo. $\mathrm{O}$ estranhamento e mesmo a repulsa e a iniciativa para o confronto direto entre grupos humanos são também associados ao etnocentrismo. 
O etnocentrismo foi tratado pela teoria evolutiva por, pelo menos, quatro técnicas de pesquisa distintas, apesar de articuladas em relação ao pressuposto da predominância da herança genética na causalidade do fenômeno. O trabalho de R. Paul Shaw (1985) é um dos pioneiros, mais influentes e polêmicos na defesa de argumentos sociobiológicos, baseados nas associações diretas entre partilha de genes e comportamentos que indicam o pertencimento a um grupo, para explicar a predisposição à guerra. Em trabalho posterior, Shaw e Wong (1989) tentam demonstrar que há uma associação direta entre o "nosso grupo" e os "nossos genes". Shaw, aliás, ironiza as análises da guerra exclusivamente orientadas por perspectivas baseadas nas dinâmicas socioculturais afirmando que os genes "mantêm a cultura na coleira".

Joshua Goldstein (1987) é um historiador dedicado a pesquisas sobre relações internacionais que critica duramente essa abordagem lembrando que os autores apenas repetem premissas da sociobiologia e desconsideram os quatro fundamentos que têm orientado a crítica à ideia de que humanos, no geral, são propensos à guerra: 1) os humanos não são inerentemente agressivos e violentos; 2) o comportamento humano é mais moldado pela cultura que por seus genes; 3 ) os agrupamentos sociais humanos não são determinados pelos genes, mas por outros fatores (ecologia, cultura, geografia, política, etc.); e 4) traços comportamentais não seriam selecionados para configuração de grupos sociais mesmo que os grupos humanos fossem definidos apenas por semelhanças genéticas.

Ross A. Hammond, do departamento de ciência política, e seu colega Robert Axelrod, da Escola Gerald F. Ford de Políticas Públicas, ambos da Universidade de Michigan, por outro lado, fizeram simulações usando teoria dos jogos baseada em princípios evolutivos para tentar oferecer explicações para o uso de critérios fenotípicos na adoção de estratégias etnocêntricas (Hammond; Axelrod, 2006).

Ainda na direção das explicações baseadas em determinismo genético encontramos o zoólogo Richard Dawkins, que, na década de 1970, tornou-se famoso ao propor que toda a vida seria regida pela necessidade de reprodução dos genes. A chamada teoria do "gene egoísta" (Dawkins, 2006), ousada e universalizante, sugere que os grupos de seres vivos baseados em herança de sangue (parentesco biológico) e as guerras clânicas são facilmente explicáveis pela teoria genética do biólogo evolucionista W. D. Hamilton, que postula uma visão da evolução concentrada no gene e atribui o altruísmo a causas genéticas. Para Dawkins somos apenas máquinas comandadas por genes. Por 
essa perspectiva, nossas guerras são, assim como as "guerras" registradas por Goodall em Gombe, em última análise, promovidas pela agência dos genes.

Carsten de Dreu é um psicólogo dedicado a estudar comportamento pela perspectiva da diversidade entre grupos e das performances coletivas. Ele e sua equipe (De Dreu et al., 2011) verificaram a presença do hormônio oxitocina em situações em que se verifica comportamento etnocêntrico. Segundo os resultados dos testes, a oxitocina aparece em situações que motivam o favoritismo no interior de um grupo e, em menor grau, na desvalorização dos que não pertencem ao grupo. Sem questionar a presença do hormônio nas situações analisadas, há um fator importante a ser considerado, que é sua presença entre humanos. Ou seja, assim como ocorre em situações em que o que está em jogo é o estresse ou o desejo sexual, a presença de hormônios é um fenômeno mensurável. Contudo, justamente por se tratar de humanos, os fatores associados precisam ser analisados como fenômenos que ocorrem num mundo cultural de significados, e não em um mundo neutro.

Em resumo, essas explicações excessivamente rígidas e essencialmente naturalísticas não se sustentam diante da prerrogativa de que os humanos operam em um universo simbólico. Dentre os vários argumentos apresentáveis destaca-se o antropológico. Segundo ele, a definição de Nós, em que pese o reconhecimento de relações de parentesco e de aliança, não se sustenta exclusivamente pela semelhança física ou pelo reconhecimento da filiação biológica, mas, sim, pelo sentimento de pertencimento a um grupo e pelo autorreconhecimento como membro de um determinado coletivo.

Isso ocorre porque, quando influenciados pelo etnocentrismo, definimos quem somos Nós e quem são os Outros a partir de julgamentos que fazemos sobre o Outro a partir dos valores e referenciais de mundo partilhados por Nós no interior de dada cultura. Em outras palavras, o etnocentrismo é um fenômeno que se sustenta por atribuições simbólicas (Mithen, 2002).

Há, por fim, uma outra abordagem, também evolucionista, mas pautada em perspectivas menos deterministas e mais relacionais. Nessa direção, o arqueólogo Steven Mithen propõe um modelo para análise da evolução da mente humana baseado em pesquisas dedicadas a analisar a evolução da inteligência, da cognição e da vida social de mamíferos, primatas em particular. Mithen (2002) trata esses resultados a partir da teoria modular da mente.

Segundo essa teoria, humanos possuem quatro módulos relacionados às inteligências natural, social, comunicativa e técnica. Segundo Mithen (2002), 
chimpanzés possuem os mesmos módulos de inteligência. Contudo, diferentemente dos chimpanzés, os humanos apresentam uma "fluidez cognitiva", ou seja, os conteúdos cognitivos de cada módulo de inteligência podem se deslocar e se unir. Para o autor, esse fenômeno é parte da história evolutiva humana, que, por sua vez, está diretamente associada à origem dos humanos comportamentalmente modernos e que possibilita, por exemplo, a associação entre elementos classificados no módulo naturalista e elementos classificados no módulo social, permitindo que nos tornássemos capazes de elaborar tanto o pensamento totêmico quanto o etnocentrismo.

Se observarmos atentamente, tanto o totemismo quanto o etnocentrismo promovem associações de semelhança, descendência ou parentesco entre humanos e não humanos (Lévi-Strauss, 1986, 2012) No caso do totemismo, é coerente associar um certo grupo humano à descendência de uma onça, de uma serpente ou de uma águia, que por sua vez podem estar associadas à floresta, aos rios e às montanhas. Tudo se articula num sentimento de pertencimento a um coletivo formados por coletivos caracterizados por uma diversidade que reúne pares que são humanos, animais e parcelas do relevo, sem que o todo seja visto como incoerente ou como uma manifestação infantil da mentalidade indígena.

No caso do etnocentrismo, podem-se observar associações elaboradas sobre o grupo vizinho, seja ele parceiro, inimigo ou competidor, em relação ao qual se pretende marcar diferenças profundas, Isso sugere um duplo potencial. De um lado, a classificação de humanos, membros de outras sociedades, usando critérios hierárquicos de inferioridade, como macacos, piolhos de macaco ou mesmo dejetos repugnantes (Boas, 2010; Lévi-Strauss, 1976) em contraste com o próprio grupo formado por seres tidos como humanos "verdadeiros". De outro lado, a associação entre seres não humanos e mesmo entre coisas e expressões de alteridade, divindade ou parentesco (Mauss, 2015).

\section{Cognição de chimpanzés: o caso do uso de ferramentas}

A descoberta da fabricação e do uso de ferramentas por chimpanzés foi uma das coisas mais incríveis do século XX, o que a tornou uma das mais importantes áreas de pesquisa em primatologia. A partir de 1990 os primatólogos ocidentais conseguiram acumular registros relevantes sobre variações em relação ao uso de ferramentas entre chimpanzés selvagens na África (McGrew, 1992; Whiten et al., 1999; Wrangham et al., 2001). 
Vale ressaltar que o interesse pelo uso de ferramentas, num esforço para aproximar humanos e chimpanzés, é fortemente influenciado pelo fato que toda exploração paleoantropológica, além dos ossos, busca, nas ferramentas, indícios para gerar modelos sobre comportamento (Klein, 2009; Mercader et al., 2007; Neves, 2013). Ao se valerem desse recurso, primatólogos visam oferecer parâmetros sustentáveis de comparação entre humanos e chimpanzés já consagrados na paleoantropologia pelas comparações entre humanos comportamentalmente modernos e hominídeos, a partir de uma perspectiva evolutiva. As ferramentas também oferecem fortes evidências acerca da variabilidade de comportamentos, numa ótica mensurável e objetiva, o que é bastante confortável para os parâmetros das práticas científicas das biociências, se comparados, por exemplo, ao comportamento social, mais movediço, nebuloso e difícil de registrar com precisão.

Muitos primatólogos chamam de "cultura material" a produção e o uso de ferramentas por chimpanzés, bem como as variações intergrupais em relação a esses padrões (Boesch, 2003; Davidson; McGrew, 2005; Gruber et al., 2009; Morgan; Abwe, 2006; O’Malley et al., 2012; Schöning et al., 2008; Van Schaik; Deaner; Merrill, 1999; Van Schaik; Pradhan, 2003; Whiten; Schick; Toth, 2009). Eles consideram que o fato de a variabilidade no uso e na produção de ferramentas não ser diretamente causada por herança genética, mas por aprendizado social, é suficiente para associar o atributo "cultural" a esses fenômenos.

Entretanto, antes de aceitar a denominação "cultura material" como adequada para o conjunto de objetos que chimpanzés usam e criam é necessário observar se ela é apenas um agregado funcional de coisas que tornam possíveis ações relacionadas à edibilidade dos recursos disponíveis ou se esses objetos, além disso, são mediadores de comportamentos que escapam da dimensão puramente funcional da existência. Para isso, tais comportamentos devem produzir sentidos para quem utiliza os objetos e os de seu grupo. As ferramentas só serão objetos culturais se possuírem este segundo atributo, mesmo que se considere, no caso das ferramentas dos chimpanzés, o altíssimo grau de inteligência relacionado à sua confecção e uso, bem como os sofisticados padrões cognitivos necessários para aprender sua confecção e funcionamento.

Considerando os artigos sobre o assunto observa-se que as variações no uso de ferramentas por chimpanzés são fortemente relacionadas à edibilidade dos recursos disponíveis e à sobrevivência no interior de um grupo. Mesmo o 
uso de ferramentas como "display social" não escapa desses referenciais. Por isso mesmo elas não são "cultura material", mas meios para manter a vida individual e coletiva.

É relevante também observar que chimpanzés usam apenas um tipo de matéria-prima para produzir cada ferramenta. Humanos, por sua vez, usam dois ou mais tipos de matéria-prima até para fazer objetos tão simples quanto um lápis. Isso depende de operações recursivas e combinatórias de caráter simbólico que são tipicamente humanas.

Mithen (2002) observa que, apesar da diversidade de matéria-prima disponível no entorno dos chimpanzés, eles escolhem apenas aquilo que é reconhecido por sua inteligência técnica. De acordo com Mithen isso ocorre porque os módulos de inteligência especializados dos chimpanzés não estão conectados. Então eles podem, por exemplo, caçar um colobus vermelho, mas não usam os ossos ou o pelo de sua presa para fazer uma ferramenta.

Os chimpanzés apreciam muito a carne desse pequeno macaco que habita as copas das árvores. Alguns grupos de chimpanzés organizam-se em estratégias coletivas de caça para obter essas presas. Entretanto, não há registros de que chimpanzés produzam um modelo abstrato de ferramenta que permita a experimentação de diferentes materiais, como ossos, dentes ou pelos, para produzi-la. Assim, as ferramentas usadas pelos chimpanzés seguem sendo produzidas a partir de pedras, pedaços de pau, folhas ou varas flexíveis. Desse modo, caçar um macaco e consumir sua carne é provavelmente uma ação relacionada ao módulo de inteligência natural, enquanto fazer ferramentas estaria associado ao módulo de inteligência tecnológica.

Sendo assim, não se observam indícios de subjetividade animal em relação ao uso de ferramentas por chimpanzés, seja porque elas não têm marcas ou adornos particulares que as associam ao seu produtor ou usuário, seja porque sua produção e uso não são formas mediadoras da expressão de uma individualidade associada a significados particulares produzidos ou atribuídos a um chimpanzé em especial.

\section{Chimpanzés têm uma teoria da mente?}

A capacidade de compreender intencionalidade surge nos humanos em seu primeiro ano de vida e a capacidade de compreender crenças em torno de quatro anos. A cognição humana opera com símbolos linguísticos e normas 
culturais, ou seja, com intencionalidade partilhada. A existência da cultura (humana) implica atividades coletivas e partilha de artefatos simbólicos (Tomasello et al., 2005).

Há, atualmente, registros da capacidade de monos em perceber a intencionalidade de outros. Contudo, isso não é suficiente para produzir atividades sociais e culturais como as humanas. Para tentar encontrar respostas, o psicólogo Michael Tomasello tem desenvolvido, no Instituto Max Planck, há alguns anos, pesquisas envolvendo a observação das capacidades cognitivas de pequenos chimpanzés e humanos, ambos na faixa etária de dois a cinco anos. A hipótese de Tomasello e de seu grupo é que os humanos expressam claramente uma "intencionalidade partilhada", ao contrário dos chimpanzés (Tomasello et al., 2005, p. 676). Formas únicas de cognição humana criaram a cultura e a possibilidade de evolução cultural (Tomasello et al., 2005, p. 690) porque humanos conseguem deixar registros sobre o que aprenderam, os quais se constituem em patrimônios culturais, e chimpanzés não fazem isso. Assim, mesmo que um chimpanzé produza algo incrível isso não se transformará em patrimônio para seu grupo ou para sua espécie.

Justamente por isso, segundo Tomasello e seu grupo, pode ser que chimpanzés tenham cultura, num sentido amplo. Contudo, isso é muito distinto do que entendemos por culturas humanas (Tomasello et al., 2005).

\section{0 debate sobre as "culturas" de chimpanzés}

A primatologia japonesa desde suas origens dialoga com a sociologia (Asquith, 1996) e procura observar e explorar as características e as dinâmicas da vida coletiva. A primatologia ocidental, por sua vez, reuniu os recursos necessários para tratar dos fenômenos verificados em campo, lentamente. O primeiro artigo que sugeriu o termo "cultura" para tratar da variação entre comportamentos verificada entre chimpanzés selvagens foi escrito por McGrew e Tutin (1978) em relação ao grooming praticado por chimpanzés na reserva de Gombe (Tanzânia) e na floresta de Taï (Costa do Marfim). Esses dois lugares figuram entre as locações em torno das quais se constituíram dois dos mais antigos centros de pesquisa contínua sobre comportamento de chimpanzés selvagens, desde a década de 1960.

William McGrew e Carole Tutin eram jovens doutorandos quando visitaram as duas áreas e perceberam as variações comportamentais nos dois 
grupos. Em seu esforço para explicar as diferenças encontraram o compêndio produzido por Kroeber e Kluckhohn (1952), que tentava oferecer subsídios.

Contudo, somente a partir do final da década de 1990 um número significativo de primatólogos passou a publicar trabalhos associando o termo "cultura" aos conjuntos de variações do comportamento que se organizam em padrões reconhecíveis para cada população de chimpanzés selvagens. O conjunto de comportamentos variantes já registrado gira em torno de 39 . Há três aspectos importantes relacionados a esses comportamentos, que são seu componente social, ou seja, eles são aprendidos no interior do grupo e não herdados; seu componente cognitivo, que implica a existência de uma capacidade de aprender tais comportamentos, e seu componente de transmissão, que está relacionado aos mecanismos associados a tal aprendizado.

As características desses comportamentos levaram os primatólogos a incorporar alguns aspectos da definição que os antropólogos culturais Alfred Kroeber e Clyde Kluckhohn sistematizaram numa iniciativa de oferecer uma definição consensual de cultura na década de 1950, que são: inovação, disseminação, estandardização, durabilidade, difusão, tradição (Lestel, 1998). A essas características McGrew e Tutin (1978) somaram a não subsistência (que corresponde a comportamentos que podem contemplar a obtenção de alimento, mas não se restringem a isso) e a naturalidade (fenômeno cuja causa não está associada à influência humana) (Lestel, 1998).

O problema é que já há muitas décadas as concepções de Kroeber e Kluckhohn são consideradas rígidas, antiquadas e deslocadas em relação às concepções contemporâneas de cultura na antropologia, que, apesar de toda a diversidade, colocam os símbolos, os significados e as formas de representação como elementos centrais e indispensáveis das culturas humanas. Ou seja, se as concepções de cultura de Kroeber e Kluckhohn servem, ou serviram inicialmente para explicar os fenômenos relativos aos chimpanzés sinalizando o ápice do conhecimento já acumulado sobre a complexidade do seu comportamento, não se pode afirmar o mesmo em relação às culturas humanas.

Assim, o descompasso permanece, em que pese a gradual aproximação da sociobiologia promovida pelos primatólogos que operam com a noção de cultura para explicar comportamento social aprendido entre chimpanzés e o consequente afastamento das ideias de Kroeber e Kluckhohn sobre cultura na antropologia. Por isso, as iniciativas das biociências pautadas na associação da cultura exclusivamente às suas bases biológicas não explicam os fenômenos 
culturais humanos nem justificam a denominação de cultura para os fenômenos identificados entre não humanos.

Há uma diferença qualitativa entre o fenômeno que a maioria dos primatólogos chama "cultura" e o fenômeno reconhecido hoje pelos antropólogos socioculturais como cultura. Os comportamentos complexos e variáveis já registrados entre chimpanzés e outros primatas não humanos são certamente expressões de sua grande complexidade social e de suas extensas capacidades cognitivas (Rapchan, 2005, 2010, 2012; Rapchan; Neves, 2005). Mas, nem por isso, são culturais.

Em relação especificamente à subjetividade, pode-se observar que a dimensão simbólica relativa à expressão da cultura exerce um papel central e indispensável. É a capacidade simbólica que oferece os elementos abstratos para a constituição da subjetividade de um indivíduo em relação a si mesmo, ao seu grupo social, a outros humanos (intersubjetividade ou etnocentrismo) e à natureza. E é também ela que possibilita a expressão da subjetividade a partir de códigos reconhecidos e elaboráveis pelo grupo de modo tal que todas as modulações realizadas pelo indivíduo através da linguagem, da arte, do comportamento ou da produção de conhecimento são, de algum modo, decodificáveis e mediam as fronteiras porosas entre o indivíduo e o coletivo. Daí a capacidade simbólica ser essencial, por essa perspectiva, na constituição da subjetividade humana.

Contudo, ao contrário dos argumentos de muitos biocientistas, tal capacidade não se resume à linguagem nem está restrita por ela. A linguagem é mais uma das formas de expressão do universo simbólico, ou abstrato, se preferirem.

\section{Nocão de pessoa: questões jurídicas, éticas e antropológicas}

No início do século XX, Marcel Mauss (1978) dedicou-se a refletir sobre a noção de "pessoa" a partir de referenciais socioantropológicos sem se preocupar em dar conta de análises linguísticas ou psicológicas. Sua proposta foi demonstrar, a partir de dados históricos e etnográficos, que a noção de "pessoa", enquanto uma das categorias do espírito humano, não é inata e está diretamente submetida a configurações sociais e culturais de cada sociedade. Segundo Mauss, as formas e razões de ser "pessoa" entre os humanos, ao mesmo tempo em que estariam submetidas às categorias aristotélicas (espaço, 
tempo, causa, todo, gênero, substância, etc.) também se pautariam no direito e na moral (costumes, religiões, estrutura social e mentalidades). Ou seja, os conteúdos relacionados a ser uma pessoa são modulados pela história e pela cultura.

Mauss (1978) defende que nunca houve cultura humana em que o equivalente à palavra "eu-mim" não tenha existido. Ou seja, em todas as culturas os seres humanos produzem significados para seu corpo e sua individualidade moral, social, espiritual e corporal. Tal reconhecimento, no entanto, também inclui a preocupação do autor em demonstrar o quanto são recentes na história humana:

- a palavra filosófica "eu";

- a "categoria do eu";

- o "culto do eu" (aberração);

- o respeito ao eu, em especial o "eu” dos outros.

Entretanto, meio século depois da primeira edição do texto de Mauss em 1938, a primatologia começou a oferecer uma profusão de dados sobre comportamentos de monos e outros primatas, ao lado de outras disciplinas, que têm colaborado para a elaboração de questões acerca dos direitos de animais não humanos ao mesmo tempo em que reforçam cogitações sobre a atribuição de alteridade a não humanos (Rapchan, 2010; Rapchan; Neves, 2014; Stanford, 1998), sobre a possibilidade de extensão da condição de pessoa a não humanos (Cavalieri; Singer, 1995; Lestel, 2004) e também exigem um debate sobre o reposicionamento ético em relação a animais não humanos (Armstrong; Botzler, 2003; Beauchamp; Frey, 2011; Gruen, 2011). Tais debates convergem, entre outras coisas, para uma tendência da filosofia chamada genericamente aqui de pós-humanismo (Teubner, 2006), mas também questionam concepções clássicas de "natureza humana" que se tornaram ultrapassadas porque elaboradas a partir do ponto de vista ocidental e patriarcal (Haraway, 1990, 2007), porque isolaram os humanos da natureza (Ingold, 1994) ou porque tentaram purificar as categorias que distinguem o humano do não humano (Latour; Woolgar, 1997).

Surgem questões como pensar juridicamente os animais como "pessoas de direitos" que implicam discutir o que é ético em termos de conduta e manejo em relação a animais que estão em cativeiro sob o controle e a 
responsabilidade de reservas, parques, zoos, laboratórios, empresas de entretenimento ou proprietários particulares.

Nesse cenário, as ciências humanas e sociais devem se reencontrar com o clássico tema das relações natureza/cultura, a fim de oferecer mais parâmetros relativos à extensão e à qualidade das interações possíveis entre humanos e não humanos - evolutivas, simbólicas ou orientadas por razões práticas (Lestel, 2004, p. 15) - diante do que se tem descoberto sobre animais não humanos e sobre o quanto se aproximam do que outrora era tomado como exclusivamente humano, retomando debates sobre como equacionar o lugar e o papel dos domínios universal e local nas interfaces com a natureza, na expressão da humanidade e na produção de culturas (Lestel, 2004, p. 132-133, 135).

De fato, e infelizmente, a amplitude do tratamento sobre quão específicos são os humanos e quais os termos das relações entre humanos e outras espécies tende a restringir-se à medida que apenas um campo de conhecimento, que se pode chamar genericamente de biociências ou de humanidades, pretenda ser o depositário de todas as respostas. Nesse sentido, são bem-vindas todas as iniciativas que se proponham a retornar às relações natureza/cultura, sob um viés interativo (Lestel, 2004, p. 15) e relacional, a partir de perspectivas inovadoras, considerando tanto os aspectos simbólico-culturais quanto as dimensões naturais da interação, encarando os animais como objetos da ciência mas também como objetos de representações e de usos práticos que, na medida em que fazem parte de nossa vida social num sentido amplo, também integram nosso universo de pensamento.

Por essa via, pode-se pensar sobre a animalidade dos seres humanos e sobre a manifestação de características outrora concebidas como exclusivamente humanas em outros seres, ao mesmo tempo em que se pode avaliar como e até onde os humanos (inclusive os cientistas) projetam a própria humanidade, externamente a si mesmos, sobre seres e entidades não humanos, ao se relacionarem com eles.

Desse modo, as aproximações conceituais entre humanos e não humanos precisam ser problematizadas adotando-se perspectivas mais plurais. Por exemplo, é valido revisitar noções tais como "comunidades", "culturas", "tradições", "sujeitos" ou "pessoas", "indivíduos" refletindo sobre os seus sentidos e considerando até que ponto elas seriam razoavelmente aplicáveis a animais não humanos, particularmente àqueles cujo comportamento depende fortemente da cognição, a qual, por sua vez, está intimamente relacionada aos 
fortes vínculos que o animal constitui com seu grupo e, eventualmente, com seres de outras espécies, como os humanos. Em contrapartida, a identificação precipitada entre humanos e outros animais pode sugerir conclusões antropomorfizantes que não são verificadas e, sim, logicamente induzidas.

Essas observações colocam a possibilidade de se refletir sobre três questões que são consequências diretas dos contatos intensos, prolongados, incomuns e profundos estabelecidos entre primatólogos e primatas não humanos nas condições dadas pelas pesquisas de campo e em laboratório a partir de sugestões levantadas pela antropóloga Pamela Asquith (2011).

De um lado, há uma tensão entre o profundo envolvimento pessoal dos pesquisadores e a necessidade de adequar a pesquisa aos rígidos padrões de objetividade postos pela sociobiologia e dominantes na primatologia, principalmente a partir da década de 1980. De outro lado, a adoção de termos correntemente usados nas ciências sociais e humanas, como "tradição", "comunidade", "cultura" ou "poder" para tratar de fenômenos associados a primatas não humanos é uma forma contemporânea e elaborada de antropomorfização que expressa tanto as simetrias identificadas pelos primatólogos em relação a outros primatas quanto seu esforço e desejo de, ao aproximar humanos de não humanos, estender tanto possibilidades teóricas e explicativas quanto direitos e proteções, na medida em que englobam humanos e não humanos sob a condição de, por exemplo, seres culturais.

Por fim, os resultados de pesquisa em primatologia obtidos nas últimas décadas somados ao grande risco a que os monos estão submetidos em vários pontos do planeta colocam questões éticas que dizem respeito à proposição e à adoção de medidas que garantam as condições de existência de indivíduos, grupos e espécies.

Outra perspectiva possível é analisar as fortes relações estabelecidas entre certos humanos e outras espécies animais (Lestel, 2004, p. 14) como associações em que se partilham não somente interesses, mas também emoções e vínculos, o que promove a emergência do que o filósofo e etólogo Dominique Lestel chamou de "comunidades híbridas" homem/animal que possibilitam a elaboração de concepções tais como "indivíduos animais" e "pessoas animais" (Lestel, 2004, p. 14). Lestel é professor e pesquisador da École des Hautes Études en Sciences Sociales e tem explorado as possibilidades de reduzir distâncias entre humanos e animais tornando as fronteiras entre ambos mais fluidas. Sua estratégia é escrutinar temas caros à filosofia, como 
a amizade por exemplo, para verificar se as definições filosóficas, clássicas e contemporâneas, excluem ou incluem os animais não humanos.

Nesses casos, a perspectiva de análise é necessariamente relacional, mas o discurso elaborado ainda não equacionou plenamente o problema de colocar os humanos como os porta-vozes, os analistas e os produtores de significados explicitados.

\section{Considerações finais}

A partir dos elementos apresentados, gostaríamos de sugerir alguns caminhos para a discussão sobre subjetividade animal enquanto categoria e pensá-la a partir de três possibilidades: como categoria possível (porque válida a partir dos fenômenos observados ou das teorias produzidas); como categoria indefinida (porque não equacionada em termos de objeto ou de método, apesar de aparecer em referências de pesquisadores); ou como categoria inviável (porque fenômenos e teorias apontam em direção oposta à sua verificação).

Para isso, optamos por explicitar algumas reflexões valendo-nos da teoria antropológica já consagrada ou nos apropriando de certos pontos de vista antropológicos para pensar sobre o que ainda não foi equacionado, mas já se manifesta como questão relevante para a reflexão sobre a subjetividade em primatas não humanos:

1) A individualidade é, como fenômeno e como categoria de pensamento, algo diferente da subjetividade. Qualquer ser vivo representa expressões de individualidade. A sua própria alimentação e reprodução, para tratar de itens básicos de sobrevivência, depende de cada indivíduo. Pesquisas recentes demonstram que até entre seres fortemente sociais, como as abelhas, operárias podem boicotar a abelha rainha e alimentar paralelamente outras larvas exclusivamente com geleia real, buscando benefício próprio (Hrdy, 1999). Já a subjetividade implica a consciência de si em alto grau e está associada à articulação simbólica de tudo que se refere ao eu, mediada pelo sentimentos, já mencionada por Damásio (2010).

Há continuidades comportamentais significativas entre humanos e outros primatas não humanos que têm sido fartamente documentadas. As explicações sobre tais fenômenos fundam-se na existência de grande proximidade genética entre as espécies e no fato de se tratar de espécies essencialmente sociais, mas há ainda muitas lacunas no conhecimento acumulado em relação a isso. 
Daí as explicações disponíveis se distribuírem num espectro que vai da opção pela predominância causal dos genes ou da vida social, em detrimento do outro fator, até as análises mais relacionais pautadas em referências que enfatizam participações equilibradas do herdado e do adquirido na configuração de certas habilidades cognitivas ou no surgimento de certas características comportamentais.

Tanto humanos quanto monos possuem um cérebro complexo que se combina com formas complexas de vida social. Nossos cérebros são dotados de características anatômico-fisiológicas herdadas, são equipados com módulos de inteligência técnica, natural, social e comunicativa (Mithen, 2002) e desenvolvem suas capacidades cognitivas em ambientes que, simultaneamente, demandam e estimulam certas habilidades, tal como o reconhecimento de faces dos membros do grupo e o interesse pelos eventos ocorridos no grupo relacionados a todo o tipo de associação ou conflito. Sexo, amizade e poder produzem vínculos sociais essenciais e conhecer sua dinâmica oferece informações igualmente essenciais. Por meio de tais informações podem-se avaliar as vantagens e riscos resultantes das associações com cada indivíduo do grupo (Dunbar, 1998).

Considerando os altos graus de neotenia verificados entre humanos e monos, que demandam cuidados ostensivos e contato dos recém-nascidos com os adultos por períodos prolongados, pode-se considerar que esses fatores indicam a existência de processos consistentes de estabelecimento de individualidades mediados tanto pelas configurações do amálgama das características de inteligência herdadas quanto pelos dos estímulos recebidos e pela vivência social.

2) O conhecimento acumulado sobre as características, complexidade e capacidades dos primatas nos coloca novos valores, padrões e compromissos éticos que precisam ser discutidos em perspectiva multidisciplinar e não podem ficar restritos ao meio acadêmico ou ao sistema jurídico, mas devem estender-se a todos os setores da sociedade.

3) Nas formas predominantemente adotadas pela primatologia na produção de conhecimento, a linguagem comum (estabelecida nas observações de campo) atribui agência aos chimpanzés enquanto a terminologia técnica (fortemente influenciada pela sociobiologia) evita isso. É fundamental que se façam análises mais profundas sobre esses registros de pesquisa, bem como sobre os mecanismos e pressupostos que orientam a produção de conhecimento na 
primatologia, para que o avanço no debate sobre as características da individualidade de primatas não humanos possa avançar.

4) A rigor, o termo "cultura de chimpanzés" e seus congêneres (como "tradição", "poder" e "capacidade simbólica") usados amplamente pelos primatólogos em seus artigos são expressões elaboradas e sofisticadas de antropomorfismo que se reproduzem amplamente na comunidade acadêmica (Asquith, 2011). As reflexões sobre a possibilidade de existência de subjetividade em seres não humanos certamente também não parecem escapar dos fatores associados às formas supramencionadas de antropomorfismo. Ou seja, o antropomorfismo pode não ser apenas a causa que leva certos pesquisadores a identificar comportamentos não humanos a comportamentos humanos, mas pode ser uma estratégia de pesquisa e aproximação, consciente ou inconsciente.

Desse modo, a suposição de existência de subjetividade pode ser a consequência da adoção de estratégias antropomorfizantes por parte dos pesquisadores, o que, por sua vez, pode ser analisável a partir de, pelo menos, quatro parâmetros: empatia em relação aos animais estudados; limitação de linguagem disponível para descrever os fenômenos observados de tal modo que o uso de expressões antropomórficas facilite descrições e compreensão; expressão das características e limites do cérebro humano em conhecer formas de vida diferentes do humano; ou ainda, talvez, o antropomorfismo seja o único, ou o melhor caminho para compreendermos certos fenômenos como, por exemplo, o comportamento, as emoções e as habilidades cognitivas de não humanos.

5) Por fim, devemos evitar confundir os atributos da espécie com os animais de dada espécie, propriamente dita, porque os primeiros são históricos, produtos do conhecimento e carregados de valores e de significados expressos em modelos e definições que visam oferecer explicações universalizantes. Já os segundos correspondem a formas de existência manifestas nos fenômenos que tentamos contemplar e compreender, com os quais interagimos diretamente e que se individualizam nas relações que estabelecemos com eles.

Tal conhecimento, atualizado no presente, pode, inclusive, num futuro não muito distante, oferecer subsídios para que se possa questionar até mesmo a validade da categoria "espécie" como um princípio classificatório válido. Por isso, que a consciência sobre as diferenças entre os modelos teóricos e os seres reais opere apenas em nível analítico e abstrato e que não seja muito 
viável para a maioria das disciplinas colocar isso em prática o tempo todo, não podemos descartar a percepção de que se trata de elementos distintos, um é o fenômeno e o outro são os mecanismos acessíveis para efetuar o reconhecimento, registro, análise e compreensão de tal fenômeno.

O arqueólogo cognitivo Stephen Mithen (2002) propõe dois modelos para representação da inteligência, a partir da análise de resultados obtidos sobre comportamento e capacidades cognitivas de chimpanzés que foram cotejados com dados e análises levantados a partir de pesquisas paleoantropológicas. Um se aplica aos nossos ancestrais e aos chimpanzés. O outro se aplica aos humanos comportamentalmente modernos.

Procurando escapar de uma concepção de mente estritamente modular, sugere que ambos possuem, ao menos, três tipos de inteligências relativas a capacidades sociais, naturalísticas e técnicas relacionadas a um módulo geral de inteligência. Ainda, segundo o modelo, apenas os humanos comportamentalmente modernos possuem uma fluidez cognitiva geral, capaz de gerar metarrepresentações ou conceitos de conceitos, como sugere o antropólogo cognitivo Dan Sperber em parceria com Hirschfeld (Sperber; Hirschfeld, 2004). Essa capacidade de produzir abstrações é plena e generalizada e remete, por sua vez, à capacidade simbólica que invade todas as nossas formas de pensar.

Essa capacidade simbólica é a responsável pelo potencial e pela habilidade de cada humano, em sua singularidade, de produzir e reproduzir significados de caráter simbólico com alcance individual ou coletivo em todos os domínios apresentados anteriormente neste artigo, ou seja, vida social; emoções, sentimentos e consciência; cognição; teoria da mente; noção de pessoa; relações híbridas entre humanos e não humanos; e cultura. Em cada um desses domínios, a expressão da singularidade se manifesta associada à produção de significados que fundamentam a possibilidade de existência de uma subjetividade que se agrega a um coletivo, pois, afinal, somos todos seres sociais.

Em outras palavras, essas questões remetem ao sempre recorrente problema da produção de sentidos. Ou seja, caso seja possível que os chimpanzés possuam "sentimentos" que possam de algum modo ser mediados por alguma das facetas de suas consciências, esse produto precisaria, ainda, adquirir sentidos e ser expresso e comunicado em consonância mínima com seus respectivos significados para que seja comensurável aos sentimentos humanos.

Em síntese, considerando as implicações do problema mencionadas acima, não é possível equivaler ou mesmo comparar os sentimentos humanos aos 
dos chimpanzés devido à ausência de um elemento explicativo central, aliás muito caro à antropologia sociocultural, que é o fato de o Homo sapiens comportamentalmente moderno produzir significados em tal grau de complexidade e profusão a ponto de contaminar, por meio de seu exercício de produção simbólica, tudo aquilo que venha a ser integrado a seu universo de pensamento, inclusive os próprios chimpanzés.

Assim, e assumindo a perspectiva segundo a qual, até o momento, as pesquisas já produzidas sobre o tema (Boesch, 1991; Biro; Matsuzawa, 2001; Crockford et al., 2004; King, 2004; Luncz; Witting; Boesch, 2015) não apresentaram resultados que tenham demonstrado expressões consistentes de capacidade simbólica em chimpanzés (Call; Tomasello, 2008), dado inclusive que a capacidade simbólica humana apresenta-se como um fenômeno total (Mauss, 2015) pois influenciou todos os domínios da mente e da vida social (Klein, 2009; Mithen, 2002; Rapchan, 2005; Rapchan; Neves, 2005) e, provavelmente, não se manifestará de outro modo, caso apareça em outra espécie, defendemos que não há resultados de pesquisas sobre primatas ou qualquer outro ser não humano capaz de expressar-se simbolicamente. Contudo, simultaneamente, não se pode descartar a recorrência dessa atitude incorrigivelmente humana, particularmente em situações de empatia profunda e contato intenso de pesquisa, inclusive quando se trata do pesquisador registrando a contrapartida "afetiva" do animal com o qual se relaciona intensamente e que resulta na projeção das habilidades humanas sobre comportamento de não humanos quando se verifica alguma semelhança entre eles. Como já sugeriram Gould e Lewontin (1979), Ingold (1990) e Galef e Heyes (1996), analogias em relação a comportamentos verificados em espécies diferentes não significam, necessariamente, identidade em termos de bases evolutivas; podem ser, simplesmente, coincidências (Rapchan, 2005, 2010). Ou seja, não basta comparar os comportamentos e verificar que eles se parecem para afirmar, com fundamentação, que eles têm a mesma história de formação.

De outro lado, numa via mais diretamente associada ao registro e análise comparativos e interespecíficos do comportamento, é provável que os primatólogos não consigam descrever a produção e a manipulação de símbolos por nossos parentes mais próximos no reino animal porque estes não possuem essa capacidade simbólica. Isso, contudo, não impede a exploração, no limite, das relações entre capacidade simbólica e habilidade para reproduzir e manipular símbolos. Pesquisas futuras sobre comunidades de humanos e não humanos 
no âmbito das relações de pesquisa, no convívio em espaços partilhados rurais e urbanos e nas representações da natureza e da cultura, por exemplo, poderão oferecer resultados relevantes e impactantes sobre as concepções vigentes acerca da definição do humano e dos novos parâmetros necessários para se considerar as relações entre humanos e não humanos.

\section{Referências}

ARMSTRONG, S. J.; BOTZLER, R. G. (Ed.). The animal ethics reader. Oxford: Oxford University Press, 2003.

ASQUITH, P. J. Japanese science and western hegemonies: primatology and the limits set to questions. In: NADER, L. (Ed.). Naked science: anthropological inquiry to boundaries, power, and knowledge. New York: Routledge, 1996. p. 239-258.

ASQUITH, P. J. Of bonds and boundaries: what is the modern role of anthropomorphism in primatological studies?. American Journal of Primatology, Hoboken, v. 73, n. 3, p. 238-244, 2011.

BEAUCHAMP, T. L.; FREY, R. G. (Ed.). The Oxford handbook of animal ethics. Oxford: Oxford University Press, 2011.

BOAS, F. A mente do ser humano primitivo. Petrópolis: Vozes, 2010.

BIRO, D.; MATSUZAWA, T. Use of numerical symbols by the chimpanzees (Pan troglodytes): cardinals, ordinals and the introduction of zero. Animal Cognition, Berlin, v. 4, n. 3-4, p. 193-199, Nov. 2001.

BOESCH, C. Teaching among wild chimpanzees, Animal Behaviour, London, v. 41, n. 3, p. 530-532, 1991.

$\mathrm{BOESCH}$, C. Is culture a golden barrier between human and chimpanzee? Evolutionary Anthropology, New York, v. 12, n. 2, p. 82-91, Apr. 2003.

BUIRSKI, P.; PLUTCHIK, R.; KELLERMAN, H. Sex differences, dominance, and personality in chimpanzees. Animal Behaviour, London, v. 26, p. 123129, 1978. 
CALL, J.; TOMASELLO, M. Does the chimpanzee have a theory of mind? 30 years later. Trends in Cognitive Sciences, London, v. 12, n. 5, p. 187-192, 2008.

CAVALIERI, P.; SINGER, P. (Ed.). The great ape project: equality beyond humanity. New York: St. Martin's Press, 1995.

CROCKFORD, C. et al. Wild chimpanzees produce group specific calls: a case for vocal learning?. Ethology, Berlin, v. 110, n. 3, p. 221-243, 2004.

THE CHIMPANZEE SEQUENCING AND ANALYSIS CONSORTIUM. Initial sequence of the chimpanzee genome and comparison with the human genome. Nature, London, v. 437, n. 7055, p. 69-87, 2005. Disponível em: $<$ http://www.nature.com/nature/journal/v437/n7055/full/nature04072.html $>$. Acesso em: 30 maio 2016.

DAMÁSIO, A. O mistério da consciência. São Paulo: Companhia das Letras, 2000.

DAMÁSIO, A. O livro da consciência: a construção do cérebro consciente. Lisboa: Temas e Debates, 2010.

DAVIDSON, I.; McGREW, W. C. Stone tools and the uniqueness of human culture. Journal of the Royal Anthropological Institute, London, v. 11, n. 4, p. 793-817, 2005.

DAWKINS, R. The selfish gene. Oxford: Oxford University Press, 2006.

De DREU, C. K. W. et al. Oxytocin promotes human ethnocentrism. Proceedings of the National Academy of Sciences of the United States of America, Washington, v. 108, n. 4, p. 1262-1266, 2011.

DUNBAR, R. The social brain hypothesis. Evolutionary Anthropology, New York, v. 6, n. 5, p. 178-190, 1998.

DUNBAR, R. The social brain: mind, language, and society in evolutionary perspective. Annual Review of Anthropology, Palo Alto, v. 32, p. 163-181, 2003. 
DUNBAR, R. Gossip in evolutionary perspective. Review of General Psychology, Washington, v. 8, n. 2, p. 100-110, 2004.

DUNBAR, R.; SCHULTZ, S. The evolution of the social brain: anthropoid primates contrast with other vertebrates. Proceedings of the Royal Society of London B, London, v. 274, n. 1624, p. 2429-2436, 2007.

FOUTS, R. O parente mais próximo. Rio de Janeiro: Objetiva, 1998.

GALEF, G. B.; HEYES, C. M. (Ed.). Social learning in animals: the roots of culture. San Diego: Academic Press, 1996.

GOLDSTEIN, J. S. The emperor's new genes: sociobiology and war. International Studies Quarterly, v. 31, n. 1, p. 33-43, 1987.

GOODALL, J. In the shadow of man. New York: Houghton Mifflin Harcourt, 1988.

GOODALL, J. Uma janela para a vida. Rio de Janeiro: Zahar, 1991.

GOULD, S. J.; LEWONTIN, R. C. The spandrels of San Marco and the Panglossian paradigm: a critique of adaptationist programme. Proceedings of the Royal Society of London B, London, v. 205, n. 1161, p. 581-598, 1979.

GRUBER, T. et al. Wild chimpanzees rely on cultural knowledge to solve an experimental honey acquisition. Current Biology, Cambridge, v. 19, n. 21, p. 1806-1810, 2009.

GRUEN, L. Ethics and animals: an introduction. Cambridge: Cambridge University Press, 2011.

HAMMOND, R. A.; AXELROD, R. The evolution of ethnocentrism. Journal of Conflict Resolution, Thousand Oaks, v. 50, n. 6, p. 926-936, 2006.

HARAWAY, D. Symians, cyborgs, and women: the reinvention of nature. New York: Routledge, 1990.

HARAWAY, D. When species meet. Minneapolis: University of Minnesota Press, 2007. 
HRDY, S. B. Mãe Natureza: uma visão feminina da evolução. Rio de Janeiro: Campus Elsevier, 1999.

INGOLD, T. An anthropologist looks at biology. Man, London, v. 25, p. 208229, 1990.

INGOLD, T. Humanity and animality. In: INGOLD, T. (Ed.). Companion encyclopedia of anthropology. London: Routledge, 1994. p. 14-32.

INGOLD, T. (Ed.). Key debates in anthropology. London: Routledge, 1996.

INGOLD, T. From complementarity to obviation: on dissolving the boundaries between social and biological anthropology, archaeology and psychology. Zeitschrift für Ethnologie, v. 123, p. 21-52, 1998.

JAHME, C. Beauty and beasts: woman, ape, and evolution. New York: Soho Press, 2001.

KING, B. J. The dynamic dance: nonvocal communication in African great apes. Cambridge: Harvard University Press, 2004.

KLEIN, R. G. The human career. Chicago: University of Chicago Press, 2009.

KROEBER, A. L.; KLUCKHOHN, C. Culture: a critical review of concepts and definitions. Cambridge: Peabody Museum, 1952. (Papers of the Peabody Museum of American Archaeology and Ethnology, Harvard University, v. 47).

LATOUR, B.; WOOLGAR, S. A vida de laboratório. Rio de Janeiro: Relume Dumará, 1997.

LEAVENS D.; AURELI, F.; HOPKINS, W. D. Behavioral evidence for the cutaneous expression of emotion in a chimpanzee (Pan troglodytes). Behaviour, Leiden, v. 141, n. 8, p. 979-997, 2004.

LÉVI-STRAUSS, C. Raça e história. In: LÉVI-STRAUSS, C. Antropologia estrutural II. Rio de Janeiro: Tempo Brasileiro, 1976. p. 328-366.

LÉVI-STRAUSS, C. Totemismo hoje. Lisboa: Ed. 70, 1986. 
LÉVI-STRAUSS, C. Estruturas elementares do parentesco. Petrópolis: Vozes, 2012.

LESTEL, D. L'innovation cognitive dans des communautés hybrides homme/ animal de partage de sens, d'intérêts et d'affects. Intellectica, Paris, v. 1-2, n. 26-27, p. 203-226, 1998.

LESTEL, D. L'animal singulier. Paris: Seuil, 2004.

LUNCZ, L. V.; WITTING, R. N.; BOESCH, C. Primate archaeology reveals cultural transmission in wild chimpanzees (Pan troglodytes verus). Philosophical Transactions of Royal Society B, London, v. 370, n. 1682, p. 1-9, Nov. 2015.

LYDDY, F. Lateral bias in chimpanzee expressions of facial emotion. Trends in Cognitive Sciences, London, v. 6, n. 9, p. 369-371, 2002.

MAUSS, M. Uma categoria do espírito humano: a noção de pessoa, a noção do EU. In: MAUSS, M. Antropologia e sociologia: vol. 1. São Paulo: EPU: Edusp, 1978.

MAUSS, M. Ensaio sobre a dádiva: forma e razão da troca nas sociedades arcaicas. In: MAUSS, M. Sociologia e antropologia. São Paulo: Cosac Naify, 2015. p. 183-294.

McGREW, W. C. Chimpanzee material culture. Cambridge: Cambridge University Press, 1992.

McGREW, W. C. Culture in nonhuman primates?. Annual Review of Anthropology, Palo Alto, v. 27, p. 301-328, 1998.

McGREW, W. C.; TUTIN, C. E. Evidence for a social custom in wild chimpanzees. Man, London, v. 13, p. 234-251, 1978.

MERCADER, J. et al. 4,300-Year-old chimpanzee sites and the origins of percussive stone technology. Proceedings of the National Academy of Sciences of the United States of America, Washington, v. 104, n. 9, p. 3043-3048, 2007.

MITHEN, S. A pré-história da mente. São Paulo: Ed. Unesp, 2002.

MORGAN, B. J.; ABWE, E. E. Chimpanzees use stone hammers in Cameron. Current Biology, Cambridge, v. 16, p. R632-633, 2006. 
NEVES, W. A. Um esqueleto incomoda muita gente.... Campinas: Ed. Unicamp, 2013.

O'MALLEY, R. C. et al. The appearence and spread of ant fishing among the Kasakela Chimpanzees of Gombe. Current Anthropology, Washington, v. 53, n. 5, p. 650-663, 2012.

RAPCHAN, E. S. Os parentes de nossos parentes: um ensaio sobre a sociedade e as culturas dos chimpanzés sob uma perspectiva antropológica. Revista de Etologia, São Paulo, v. 6, n. 2, p. 101-117, 2004.

RAPCHAN, E. S. Chimpanzés possuem cultura? Questões para a antropologia sobre um tema "bom para pensar". Revista de Antropologia, São Paulo, v. 48, n. 1, p. 227-280, 2005.

RAPCHAN, E. S. Sobre o comportamento de chimpanzés: o que antropólogos e primatólogos podem ensinar sobre o assunto?. Horizontes Antropológicos, Porto Alegre, ano 16, n. 33, p. 227-266, 2010.

RAPCHAN, E. S. Cultura e inteligência: reflexões antropológicas sobre aspectos não físicos da evolução em chimpanzés e humanos. História, Ciências, Saúde - Manguinhos, Rio de Janeiro, v. 19, n. 3, p. 793-813, jul./ set. 2012.

RAPCHAN, E. S.; NEVES, W. A. Chimpanzés não amam! Em defesa do significado. Revista de Antropologia, São Paulo, v. 48, n. 2, p. 649-698, 2005.

RAPCHAN, E. S.; NEVES, W. A. Etnografias sobre humanos e não humanos: limites e possibilidades. Revista de Antropologia, São Paulo, v. 57, n. 1, p. 33$85,2014$.

SCHÖNING, C. et al. The nature of culture: technological variation in chimpanzee predation on army ants revisited. Journal of Human Evolution, London, v. 55, n. 1, p. 48-59, 2008.

SHAW, R. P. Humanity's propensity for warfare: a sociobiological perspectives. Canadian Review of Sociology \& Anthropology, Toronto, v. 22, n. 2, p. 159183, 1985. 
SHAW, R. P.; WONG, Y. The genetic seeds of warfare: evolution, nationalism, and patriotism. Boston: Unwin Hyman, 1989.

SPERBER, D.; HIRSCHFELD, L. A. The cognitive foundations of cultural stability and diversity. Trends in Cognitive Sciences, London, v. 8, n. 1, p. 4046, 2004.

STANFORD, C. B. The social behavior of chimpanzees and bonobos. Current Anthropology, Chicago, v. 39, n. 4, p. 399-420, Aug.-Oct. 1998.

TEUBNER, G. Rights of non-humans? Electronic agents and animals as new actors in politics and law. Journal of Law and Society, Hoboken, v. 33, n. 4, p. 497-521, 2006.

TOMASELLO, M. et al. Understanding and sharing intentions: the origins of cultural cognition. Behavioral and Brain Sciences, New York, v. 28, n. 5, p. $675-735,2005$.

VAN SCHAIK, C. P.; DEANER, P. O.; MERRIL, M. Y. The conditions for tool use in primates: implications for the evolution of material culture. Journal of Human Evolution, London, v. 36, n. 6, p. 719-741, 1999.

VAN SCHAIK, C. P.; PRADHAN, G. R. A model for tool-use traditions in primates: implications for the coevolution of culture and cognition. Journal of Human Evolution, London, v. 44, n. 6, p. 645-664, 2003.

WHITEN, A.; SCHICK, K.; TOTH, N. The evolution and cultural transmission of percussive technology: integrating evidence from paleoantropology and primatology. Journal of Human Evolution, London, v. 57, n. 4, p. 420-435, 2009.

WHITEN, A. et al. Culture in chimpanzees. Nature, London, v. 399, n. 6737, p. $682-685,1999$.

WRANGHAM, R. W. A. et al. (Ed.). Chimpanzee cultures. Cambridge: Harvard University Press: Chicago Academy of Sciences, 2001. 